\title{
Applications of Metal Compound Nanomaterials in Quantum Dot Sensitized Solar Cells (QDSSC)
}

\author{
R. K. Das \\ Dept. of Physics, Charuchandra College, University of Calcutta, Kolkata, India \\ *Corresponding Author: rkdas_171171@rediffmail.com \\ Available online at: www.isroset.org \\ Receive $04^{\text {th }}$ Sep 2017, Revised $16^{\text {th }}$ Sep 2017, Accepted $19^{\text {th }}$ Oct 2017 , Online $30^{\text {th }}$ Oct 2017
}

\begin{abstract}
Here we have discussed the role of compound of metals such as $\mathrm{ZnO}, \mathrm{TiO}_{2}, \mathrm{PbS}$ nanomaterials in QDSSC. Quantum dots have many advantages such as they form bilayer structure on the top of metal oxide, besides this it provides good carrier pathways and large interface areas for collection of carriers. $\mathrm{PbS}$ is used as photovoltaic material in near IR region. $\mathrm{PbS}$ quantum dots have also number of applications such as in nanotechnology, light emitting diodes and solar cells. In Quantum dots due to high level control over the size of crystals it is possible to have control over the band gap and conductive properties of the materials. This property makes quantum dots suitable for solar cells. Semiconductor quantum dots such as $\mathrm{CdSe}, \mathrm{InP}, \mathrm{InAs}, \mathrm{PbS}, \mathrm{PbSe}$ are used in solar cells. Cobalt nanoparticles are used in solar energy absorption and magnetic recording data purposes. QDSSC are less expansive and highly efficient in comparison to traditional solar cells.
\end{abstract}

Keywords-Metal Oxide, Quantum Dots, Solar cell, Nanomaterials, Band gap

\section{INTRODUCTION}

Metal compounds such as $\mathrm{ZnO}, \mathrm{TiO}_{2}, \mathrm{PbS}$ nanomaterials have huge applications in Quantum Dot Sensitized Solar Cells (QDSSC). Quantum dots (QDs) are the compound semiconductors which are the excellent constituent materials for solar cells for their properties like intense excitation absorption bands which are tuned by selecting suitable semiconductors compositions and also the size that cover the entire solar spectral region [1]. QD-based solar cells have been used in different of cell structures [2-6]. Metal oxide Quantum dots-based solar cells have bilayer structures with a QD layer formed on top of a metal oxide layer [7-9]. Another advantage of a metal oxide nanorods is that it provides good carrier pathways and also provides large interface areas for carrier collection [10-14]. PbS Quantum Dots are widely used as photovoltaic materials in near Infra Red region. Semiconductor quantum dots (QDs) have excellent optoelectronic properties [15]. Properties like size tunable absorption, high optical extinction coefficient and multiple excitation generation of semiconductor QDs are suitable for absorbing light in solar cells. The QD-sensitized solar cell is similar to the dye-sensitized solar cell, if the dye is replaced by QDs.

Quantum confinement of excitation helps in limited pathways for de-excitation of electron and hole pairs showing slow cooling dynamics [16]. This slow cooling dynamics in QDs can increase the probability of multiple excitation generation, here a high energy photon ( $>2 \mathrm{Eg}, \mathrm{Eg}$ is the band gap energy) can give two or more electron-hole pairs. This phenomenon has great application for new generation photovoltaic of QDs $[17,18]$. PbS (lead Sulphide) has properties like direct energy band gap of $0.41 \mathrm{eV}$ at 300 $\mathrm{K}$, which corresponds to the absorption onset of $3024 \mathrm{~nm}$, large Bohr excitation radius of $18 \mathrm{~nm}$, high dielectric constant of 18, small effective masses of electron and hole $\left(\mathrm{m}_{\mathrm{e}}^{*}=\mathrm{m}_{\mathrm{h}} *=0.085 \mathrm{~m}_{\mathrm{e}}\right)$ [19]. Due to these properties, PbS QDs have numerous applications in nanotechnology, near-IR communication, biomedical imaging, bio sensing, window coatings, infrared detectors, optical switches, light-emitting diodes and solar cells [20-26]. Cobalt nanoparticles due to its unique electrical, optical and magnetic properties can be used in solar energy absorption and magnetic recording data purposes [27]. The ability to tune the size of quantum dots is advantageous for many applications in solid-state quantum computation, Solar cells and Photovoltaic devices, Light emitting devices, Photo detector devices and Medical imaging and disease detection. Due to the smaller size of the crystal, the larger energy band gap, there is greater difference in energy between the highest valence band and the lowest conduction band, therefore more energy is required to excite the quantum dot and concurrently more energy is released when the crystal returns to its initial state. This equates to higher frequencies of light emitted after excitation of the quantum dots as the crystal size grows smaller, showing colour change from red to blue in the emitted light.

The main advantage with quantum dots is that because of high level of control over the size of crystals produced, it is possible to have a control over the band gap as well as the conductive properties of the material. This property makes quantum dots desirable for solar cells. Traditional solar cells 
are made of semiconductors and expensive to produce. Also the efficiency was not so high as compared to QDSSC.

This paper gives brief review of the properties and applications of some metal compound nanomaterials in Quantum Dot Sensitized Solar Cells (QDSSC) which have great importance in nano technology.

This paper has been written into three distinct sectionsIntroduction, Mechanism and conclusion. Introduction section contains a brief review of literature related to topic of this paper. Mechanism section deals with the mechanism of charge transfer processes taking place in semiconductor nanocrystals for which they have importance in nanotechnology. Conclusion part gives the major conclusion drawn in this paper.

\section{MEChANISM}

Semiconductor nanocrystals which are the building blocks of nanotechnology have been widely used in solar cells. Three major ways of using semiconductor dots in solar cell are (i) metal-semiconductor or Schottky junction photovoltaic cell (ii) polymer-semiconductor hybrid solar cell, and (iii) quantum dot sensitized solar cell.

We are here interested in third process. Charge separation and recombination reaction in semiconductor nanocrystal when subjected to band gap excitation is given by

$\mathrm{CdSe}+\mathrm{h} v \rightarrow \operatorname{CdSe}\left(\mathrm{e}_{\mathrm{p}}+\mathrm{h}_{\mathrm{p}}\right) \rightarrow \mathrm{CdSe}\left(\mathrm{e}_{\mathrm{s}}+\mathrm{h}_{\mathrm{s}}\right) \ldots \ldots$ (1) (Charge separation reaction)

CdSe $\left.\left(\mathrm{e}_{\mathrm{s}}+\mathrm{h}_{\mathrm{s}}\right) \rightarrow \mathrm{CdSe}+\mathrm{h} v^{\prime} \ldots \ldots \ldots \ldots \ldots \ldots \ldots . . . . . . .2\right) \quad$ (Charge recombination reaction)

Subscripts $\mathrm{s}$ and $\mathrm{p}$ refer to the electronic states of the electrons (e) and holes (h) [28].

when the holes and electrons get collected in the conduction and valence bands, then there is a absorption. The charge separated state usually follows the emission decay or there is recovery of the transient bleaching. The major deactivation process for the quenching of emission is the electron transfer between excited $\mathrm{CdSe}\left(\mathrm{Cadmium}\right.$ Selenide) and $\mathrm{TiO}_{2}$ (Titanium Dioxide) and the reaction is

$\mathrm{CdSe}\left(\mathrm{e}_{\mathrm{s}}+\mathrm{h}_{\mathrm{s}}\right)+\mathrm{TiO}_{2} \rightarrow \mathrm{CdSe}(\mathrm{h})+\mathrm{TiO}_{2}(\mathrm{e})$

It has been seen that CdSe Nano rod samples with length $(\sim 30 \mathrm{~nm})$ with different diameters which are $2.5 \mathrm{~nm}$ and 8.0 $\mathrm{nm}$, show 8 times faster intra band energy relaxation in the case of thicker rods than thin rods[29]. The excited CdSe quantum dots inject electrons into $\mathrm{TiO}_{2}$ (Titanium dioxide) nanoparticles [30-31]. The $\mathrm{TiO}_{2}$ particle has a band gap of $3.2 \mathrm{eV}$, so it exhibit absorption in the UV region having onset around 390nm. Because of the small electron effective mass $\mathrm{m}_{\mathrm{e}}=0.13 \mathrm{~m}_{\mathrm{o}}$ and the larger hole mass $\mathrm{m}_{\mathrm{h}}=1.14 \mathrm{~m}_{\mathrm{o}}$, most of the band gap increase shift in the conduction band towards more negative potentials [32]. So CdSe quantum dots with their increased band gaps are having favourable conduction band energies for injecting electrons into $\mathrm{TiO}_{2}$ (reaction 3). By coupling semiconductor having a short energy band gap such as CdSe with another semiconductor with suitable energy, it is possible to increase the efficiency of charge separation by rectification of charge [33]. By matching the conduction and valence bands of the two semiconductors it is possible to capture the charge carriers at the electrode surface. Semiconductor quantum dots such as $\mathrm{CdSe}$, InP, InAs, $\mathrm{PbS}$, and $\mathrm{PbSe}$ can be used for harvesting light energy in the visible region. CdTe nanomaterials helps in spatial charge separation between $\mathrm{CdTe}(\mathrm{Cadmium}$ Telluride) and CdSe(Cadmium Selenide) nanomaterials [34]. Fast capture of electrons at the quantum dot interface is a major challenge for harvesting light energy in visible range. This is very important for multiple charge carrier generation leading to photocurrent generation. Use of CdSe quantum dots on a semiconductor nanotube can be used to capture and transport photo generated electrons thus producing photocurrent.

\section{CONCLUSION}

In summary, Compounds of metal nanostructure such as $\mathrm{ZnO}, \mathrm{TiO}_{2}, \mathrm{PbS}$ play important role in QDSSC. And semiconductor Quantum Dots such as CdSe, InP, InAS, PbS, $\mathrm{PbSe}$ are also used in solar cells as they can harvest light energy in visible range. $\mathrm{PbS}$ quantum dots is used as photovoltaic material in near IR region. Due to their extraordinary unique properties they are used in Quantum Dot Sensitized Solar Cells. Cobalt nanoparticles are used in solar energy absorption and magnetic recording data purposes.

\section{Acknowledgment}

I am thankful to Department of Physics, Charuchandra College, University of Calcutta for giving me support.

\section{References}

[1] J. A. Tang, E. H. Sargent, "Infrared Colloidal Quantum Dots for Photovoltaics: Fundamentals and Recent Progress", Advanced Materials, vol.23, pp.12-29, 2011.

[2] I. Robel, V. Subramanian, M. Kuno, P. V. Kamat, "Quantum Dot Solar Cells. Harvesting Light Energy with CdSe Nanocrystals Molecularly Linked to Mesoscopic TiO2 Films", Journal of American Chemical Society, vol 128, pp.2385-2393, 2006.

[3] J. M. Luther, M. Law, M. C. Beard, Q Song, M.O. Reese, R. J. Ellingson, A. J. Nozik, "Schottky Solar Cells Based on Colloidal Nanocrystal Films", Nano Letters, vol.8, pp. 3488-3492, 2008.

[4] J. J. Choi, Y. F. Lim, M. B. Santiago-Berrios, M. Oh, B. R. Hyun, L. F. Sung, A. C. Bartnik, A. Goedhart, G. G. Malliaras, H. D. Abruna, "PbSe Nanocrystal Excitonic Solar Cells", Nano Letters, vol.9, pp.3749-3755, 2009.

[5] E. H. Sargent, "Colloidal Quantum Dot Solar Cells", Nature Photonics, vol 6, pp.133-135, 2012. 
[6] P. V. Kamat, "Quantum Dot Solar Cells, The Next Big Thing in Photovoltaics”, Journal of Physical Chemistry Letters, vol.4, pp.908918, 2013.

[7] K. S. Leschkies, T. J. Beatty, M. S. Kang, D. J. Norris, E. S. Aydil, "Solar Cells Based on Junctions between Colloidal PbSe Nanocrystals and Thin ZnO Films", ACS Nano, vol.3, pp.3638-3648, 2009.

[8] H. Liu, J. Tang, I. J. Kramer, R. Debnath, G. I. Koleilat, X. H. Wang, A. Fisher, R. Li, L. Brzozowski, L. Levina, "Electron Acceptor Materials Engineering in Colloidal Quantum Dot Solar Cells", Advanced Materials, vol. 23, pp.3832-3837, 2011.

[9] A. G. Pattantyus-Abraham, I. J. Kramer, A. R. Barkhouse, X. H. Wang, G. Konstantatos, R. Debnath, L. Levina, I. Raabe, M. K. Nazeeruddin, M. Grätzel, "Depleted-Heterojunction Colloidal Quantum Dot Solar Cells”, ACS Nano, vol.4, pp.3374-3380, 2010.

[10] X. Z. Lan, J. Bai, S. Masala, S. M. Thon, Y. Ren, I. J. Kramer, S. Hoogland, A. Simchi, G. I. Koleilat, D. Paz-Soldan, "Self-Assembled, Nanowire Network Electrodes for Depleted Bulk Hetero junction Solar Cells", Advanced Materials, vol.25, pp.1769-1773, 2013.

[11] K.S. Leschkies, A. G. Jacobs, D. J. Norris, E. S. Aydil, "NanowireQuantum-Dot Solar Cells and the Influence of Nanowire Length on the Charge Collection Efficiency", Applied Physics Letters, vol.95, Issue 19, Article ID.193103, 2009.

[12] I. J. Kramer, D. Zhitomirsky, J. D. Bass, P. M. Rice, T. Topuria, L. Krupp, S. M. Thon, A. H. Ip, R. Debnath, H. C. Kim, ”Ordered Nanopillar Structured Electrodes for Depleted Bulk Hetero junction Colloidal Quantum Dot Solar Cells”, Advanced Materials, vol.24, pp.2315-2319, 2012.

[13] H. Park, S. Chang, J. Jean, J. J. Cheng, P. T. Araujo, M. S. Wang, M. G. Bawendi, M. S. Dresselhaus, V. Bulović, J. Kong, "Graphene Cathode-Based ZnO Nanowire Hybrid Solar Cells." Nano Letters, vol.13, pp.233-239, 2013

[14] J. Jean, S. Chang, P. R. Brown, J. J. Cheng, P. H. Rekemeyer, M. G. Bawendi, S. Gradecak, V. Bulovic, "ZnO Nanowire Arrays for Enhanced Photocurrent in PbS Quantum Dot Solar Cells”, Advanced Materials, vol.25, pp.2790-2796, 2013.

[15] Photovoltaic Laboratory, Centre for Energy Studies, Indian Institute of Technology Delhi, Hauz Khas, New Delhi 110016, India.

[16] A. J. Nozik, "Exciton Multiplication and Relaxation Dynamics in Quantum Dots: Applications to Ultrahigh-Efficiency Solar Photon Conversion, ”, Inorganic Chemistry , vol.44 , pp.6893-6899, 2005.

[17] A.J. Nozik, M.C. Beard, J.M. Luther, M. Law, R.J. Ellingson, J.C. Johnson," Semiconductor Quantum Dots and Quantum Dot Arrays and Applications of Multiple Exciton Generation to Third-Generation Photovoltaic Solar Cells”, Chemical Reviews, vol.110, pp.6873-6890, 2010.

[18] A. J. Nozik, "Multiple exciton generation in semiconductor quantum dots", Chemical Physics Letters ,vol.457, pp.3-11, 2008.

[19] A. H. Souici, N. Keghouche, J. A. Delaire, H. Remita, A. Etcheberry, M. Mostafavi, "Structural and Optical Properties of PbS
Nanoparticles Synthesized by the Radiolytic Method", Journal of Physical Chemistry C, vol.113, pp. 8050-8057, 2009.

[20] W.W. Scanlon, "Intrinsic Optical Absorption and the Radiative Recombination Lifetime in PbS”, Physical Review, vol.109, pp. 47-50, 1958.

[21] M. Mozafari, F. Moztarzadeh, “Green synthesis of well-defined spherical PbS quantum dots and its potential in biomedical imaging research and bio sensing”, IEEE ,vol.978, pp.100-103, 2011.

[22] Y. Ni, H. Liu, F. Wang, Y. Liang, J. Hong, X. Ma, Z. Xu, “PbS nanostructures synthesized via surfactant assisted mechanochemical route”, Crystal Research and Technology, vol. 39, pp.200-206, 2004.

[23] P. Gadenne, Y. Yagil, G. Deutscher, "Transmittance and reflectance in situ measurements of semicontinuous gold films during deposition", Journal of Applied Physics, vol. 66, pp.3019-3025, 1989.

[24] R. S. Kane, R. E. Cohen, R. Silbey, "Theoretical Study of the Electronic Structure of PbS Nanoclusters", Journal of Physical Chemistry, vol.100, pp.7928-7932, 1996.

[25] J. J. Peterson, T. D. Krauss, "Fluorescence Spectroscopy of Single Lead Sulfide Quantum Dots”, Nano Letters, vol.6, pp.510-514, 2006.

[26] N. Zhao, T. P. Osedach, L.Y. Chang, S.M. Geyer, D. Wanger, T. Maddalena, A.C. Arango, M.G. Bawendi, V. Bulovic, "Colloidal PbS Quantum Dot Solar Cells with High Fill Factor”, ACS Nano, vol.4, pp. 3743-3752, 2010.

[27] G. Chandraprabha, T. Sankarappa, T.Sujatha, "Structure and magnetic studies of Cobalt Nanoparticles prepared by Modified Polyol Process", International Journal of Scientific Research in Physics and Applied Sciences, vol.5, Issue 4, pp. 17-20, 2017,

[28] W. U. Huynh, J. J. Dittmer, A. P. Alivisatos, "Investigation of Properties of $\mathrm{ZnO}$ Nanorad Structures by Chemical Vapor Deposition," Science, vol.295, pp.2425-2427, 2002.

[29] C. J. Brabec, N. S. Sariciftci, J. C. Hummelen, "Origin of the Open Circuit Voltage of Plastic Solar Cells" ,Advanced Functional Materials, vol.11, pp.15-26, 2001.

[30] M. H. Huang, Y. Wu, H. Feick, N. Tran, E.Weber, P.Yang, "Catalytic growth of zinc oxide nanowires by vapour transport", Advanced Materials, vol.13, pp.113-116, 2001.

[31] Y.C. Kong, D.P. Yu, B. Zhang,W. Fang, S.Q. Feng, "Ultravioletemitting ZnO nanowires synthesized by a physical vapor deposition approach", Applied Physics Letters, vol.78, pp.407-409, 2001.

[32] B. Pradhan, A. Bandyopadhyay, A. J Pal, "Tuning performance of donor-acceptor based self-assembled photovoltaic devices”, Applied Physics Letters,vol.85, pp.633, 2004.

[33] J.-J. Wu, S.-C. Liu, "Low-Temperature and Catalyst-Free Synthesis of Well-Aligned ZnO Nanorods on Si (100)", Advanced Materials, vol.14, pp.215-218, 2002.

[34] J.-J. Wu, S.-C. Liu, “Catalyst-Free Growth and Characterization of ZnO Nanorods,",Journal of Physical Chemistry B, vol.106, pp.95469551, 2002.

\section{Author Profile}

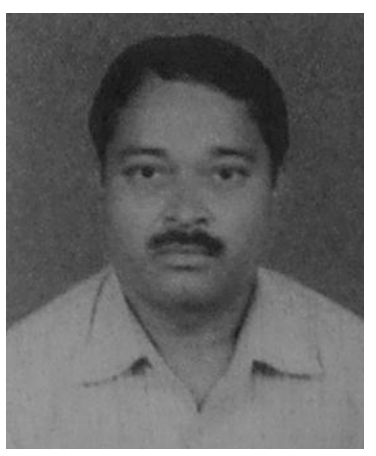

Mr. R.K. Das has completed B.Sc from St. Paul's Cathedral Mission College under university of Calcutta. He has completed M.Sc in physics from Calcutta University. He has been working (Lecturer and Assistant Professor Stage II) with Department of Physics, Charuchandra College, Kolkata which is affiliated to Calcutta University for 15 years. He has 6 research publications and 4 papers have been communicated till now. And his research topic is basically electronics. He has taught Physics for 15 years and basically the topics are Electronics, Quantum Mechanics, Classical Mechanics, Electrodynamics, Magnetism, Thermodynamics, Electromagnetic Theory, Solid State Physics, Relativity. Presently he is continuing in his teacher job. 